\title{
Appraisal of the faecal haemoglobin, age and sex test (FAST) score in assessment of patients with lower bowel symptoms: an observational study
}

\author{
Jayne Digby ${ }^{1}$, Judith A. Strachan ${ }^{2}$, Craig Mowat ${ }^{3}$, Robert J. C. Steele ${ }^{4}$ and Callum G. Fraser ${ }^{5^{*}}$ (D)
}

\begin{abstract}
Background: Many patients present in primary care with lower bowel symptoms, but significant bowel disease $(\mathrm{SBD})$, comprising colorectal cancer (CRC), advanced adenoma (AA), or inflammatory bowel disease (IBD), is uncommon. Quantitative faecal immunochemical tests for haemoglobin (FIT), which examine faecal haemoglobin concentrations $(f-H b)$, assist in deciding who would benefit from colonoscopy. Incorporation of additional variables in an individual riskscore might improve this approach. We investigated if the published $\mathbf{f}-\mathrm{Hb}$, age and sex test score (FAST score) added value.
\end{abstract}

Methods: Data from the first year of routine use of FIT in primary care in one NHS Board in Scotland were examined: $f-$ $\mathrm{Hb}$ was estimated using one HM-JACKarc FIT system (Kyowa Medex Co., Ltd., Tokyo, Japan) with a cut-off for positivity $\geq 10 \mu \mathrm{g} \mathrm{Hb} / \mathrm{g}$ faeces. 5660 specimens were received for analysis in the first year. 4072 patients were referred to secondary care: 2881 (70.6\%) of these had returned a FIT specimen. Of those referred, 1447 had colonoscopy data as well as the $\mathrm{f}-\mathrm{Hb}$ result (group A): 2521 patients, also with $\mathrm{f}-\mathrm{Hb}$, were not immediately referred (group B). The FAST score was assessed in both groups.

Results: 1196 (41.7\%) of patients who returned a specimen for FIT analysis had f-Hb $\geq 10 \mu \mathrm{g} \mathrm{Hb} / \mathrm{g}$ faeces. In group A, 252 of 296 (85.1\%) with SBD had $\mathrm{f}-\mathrm{Hb} \geq 10 \mu \mathrm{g} \mathrm{Hb} / \mathrm{g}$ faeces, as did 528 of 1151 (45.8\%) without SBD Using a FAST score $\geq 2.12$, which gives high clinical sensitivity for CRC, only 1143 would have been referred for colonoscopy (21.0\% reduction in demand): 286 of 296 (96.6\%) with SBD had a positive FAST score, as did 857 of 1151 (74.5\%) without SBD. However, one CRC, five AA and four IBD would have been missed. In group B, although $95.2 \%$ had $\mathrm{f}-\mathrm{Hb}<10 \mu \mathrm{g} \mathrm{Hb} / \mathrm{g}$ faeces, 1371 (53.7\%) had FAST score $\geq 2.12$ : clinical rationale led to only 122 of group B completing subsequent bowel investigations: a FAST score $\geq 2.12$ was found in 13 of $15(86.7 \%)$ with SBD.

Conclusions: The performance characteristics of the FAST score did not seem to enhance the utility of $\mathrm{f}-\mathrm{Hb}$ alone. Locally-derived formulae might confer desired benefits.

Keywords: Adenoma, Bowel disease, Colorectal cancer, Faecal biomarkers, Faecal haemoglobin, Faecal immunochemical test, FAST score, Inflammatory bowel disease

\footnotetext{
* Correspondence: callum.fraser@nhs.net; c.g.fraser@dundee.ac.uk

${ }^{5}$ Centre for Research into Cancer Prevention and Screening, University of

Dundee, Ninewells Hospital and Medical School, Dundee, Scotland DD1 9SY,

UK

Full list of author information is available at the end of the article
}

(c) The Author(s). 2019 Open Access This article is distributed under the terms of the Creative Commons Attribution 4.0 International License (http://creativecommons.org/licenses/by/4.0/), which permits unrestricted use, distribution, and reproduction in any medium, provided you give appropriate credit to the original author(s) and the source, provide a link to the Creative Commons license, and indicate if changes were made. The Creative Commons Public Domain Dedication waiver (http://creativecommons.org/publicdomain/zero/1.0/) applies to the data made available in this article, unless otherwise stated. 


\section{Background}

Faecal immunochemical tests (FIT) for haemoglobin ( $\mathrm{Hb})$ are widely used in opportunistic and programmatic screening for colorectal cancer (CRC) in asymptomatic populations [1]. However, most cases of CRC in the United Kingdom (UK), and probably elsewhere, are diagnosed after referral from primary to secondary care [2]. A difficulty in practice is that very many patients present with lower bowel symptoms in primary care, but significant bowel disease (SBD: colorectal cancer [CRC], advanced adenoma $[\mathrm{AA}]$, sometimes precursors of CRC, or inflammatory bowel disease [IBD]) is uncommon. Symptoms have been well documented to have poor diagnostic accuracy for SBD $[3,4]$. However, the faecal haemoglobin concentration ( $\mathrm{f}-\mathrm{Hb}$ ), as determined by quantitative FIT, has been proven to be of considerable value in the assessment of symptomatic patients [5-7]. The National Institute for Health and Care Excellence (NICE) in England has developed diagnostic guidance (DG30) [8] which states that: quantitative FIT are recommended for adoption in primary care to guide referral for suspected colorectal cancer in people without rectal bleeding who have unexplained symptoms but do not meet the criteria for a suspected cancer pathway referral outlined in NICE's guideline on suspected cancer (NG12) [9]. DG30 also states that results should be reported using a threshold (cut-off) of $10 \mu \mathrm{g} \mathrm{Hb} / \mathrm{g}$ faeces [8]. However, a number of very real challenges still confound the introduction of FIT in assessment of patients presenting in primary care with lower bowel symptoms [10], which include rectal bleeding, a change in bowel habits, weight loss, anaemia, abdominal pain and blood in faeces [8].

It has been proposed that prediction or risk-scoring models, which combine symptoms and/or known risk factors for SBD with $\mathrm{f}-\mathrm{Hb}$, might improve the use of $\mathrm{f}$ $\mathrm{Hb}$ alone [11]. A CRC prediction model, COLONPREDICT, based on both clinical and laboratory findings, was developed by Cubiella et al., who compared its diagnostic accuracy with the 2015 version of the NICE NG12 referral criteria and externally validated the strategy: it was concluded that COLONPREDICT was a highly accurate prediction model for CRC detection [12]. The final prediction model included 11 variables and, in consequence, we thought that this complexity might make this approach unlikely to be used in routine primary care practice. Since we have demonstrated that $\mathrm{f}-\mathrm{Hb}$ is affected by age and sex, with $\mathrm{f}-\mathrm{Hb}$ rising with age and being higher in men than women [13], an international multi-centre collaboration led to development and validation of the FAST score, which combines $\mathbf{f}-\mathrm{Hb}$ and age and sex as a single test result which might indicate individual risk of CRC and SBD [14]. The developers considered that the FAST score was easy to calculate and was highly accurate for CRC detection in symptomatic patients. Interestingly, the validation cohort included heterogeneous data from three studies in Scotland as well as two studies in different regions of Spain, using a number of different FIT analytical systems, and it appeared that the FAST score was equally clinically sensitive for $\mathrm{CRC}$, regardless of country, prevalence of disease, age, sex, healthcare level (primary or secondary) and analytical system used to estimate $\mathrm{f}-\mathrm{Hb}$. However, it was admitted that the diagnostic accuracy and applicability of the FAST score in a primary care setting had still to be investigated objectively.

Recently, a comprehensive diagnostic accuracy study was performed in Spain with data from the 1572 patients in the COLONPREDICT cohort [15]. The conclusion was that referral criteria based on $\mathrm{f}-\mathrm{Hb}$, used either on its own or as a component of two prediction models, COLONPREDICT and the FAST score, are more accurate than symptom-based referral criteria for CRC detection in patients presenting with lower bowel symptoms. The symptom-based criteria examined included those currently used in the UK 2017 update of the NICE NG12 strategy [9], which was disseminated following publication of NICE DG30 [8]. However, it is not known to date whether use of the FAST score, rather than $\mathrm{f}-\mathrm{Hb}$ along with clinical impressions and perhaps the use of other routine tests including the full blood count, would add value in different geographical settings and using different criteria for referral for colonoscopy and different FIT analytical systems. This study aimed to perform an initial evaluation of the utility of the FAST score in patients presenting in primary care for investigation of lower bowel symptoms, in one region of Scotland, over the first year of routine use of FIT.

\section{Methods}

Data from the first year of routine use of $\mathrm{f}-\mathrm{Hb}$ in NHS Tayside, Scotland, were included in our examination of the use of the FAST score: the full details of the evaluation of the impact of introducing a FIT for into primary care on the outcome of patients with new bowel symptoms have been published [16]. In brief, since December 2015, general practitioners (GP) were encouraged to request a FIT when evaluating patients presenting with new lower bowel symptoms. FIT kits, comprising one specimen collection device (Kyowa Medex Co., Ltd., Tokyo, Japan) along with pictorial instructions and a return envelope, were provided to patients by general practitioners (GP). When a FIT sample was returned to the laboratory, $\mathrm{f}-\mathrm{Hb}$ was estimated using one HMJACKarc FIT system (Kyowa Medex). Samples with results above the upper analytical limit were not diluted and re-analysed but reported as $\geq 400 \mu \mathrm{g} \mathrm{Hb} / \mathrm{g}$ faeces. Results with $\mathrm{f}-\mathrm{Hb}<400 \mu \mathrm{g} \mathrm{Hb} / \mathrm{g}$ faeces but $\geq 10 \mu \mathrm{g} \mathrm{Hb} / \mathrm{g}$ faeces were defined as positive and reported numerically. 
The cut-off $\mathrm{f}-\mathrm{Hb}$ was as recommended in NICE DG30 [8]: results $<10 \mu \mathrm{g} \mathrm{Hb} / \mathrm{g}$ faeces were reported as $\mathrm{f}-\mathrm{Hb}$ not detected. The reports also directed GP to the NHS Tayside gastroenterology website, which advised that $\mathrm{f}$ $\mathrm{Hb}<10 \mu \mathrm{g} \mathrm{Hb} / \mathrm{g}$ faeces, in the absence of iron deficiency anaemia (IDA), rectal bleeding, or a mass, suggests that SBD is extremely unlikely. All requests for further investigation in secondary care were made through a unique electronic portal. Age and sex were determined from the Community Health Index (CHI), a unique 10-digit patient identifier used throughout primary and secondary care in NHS Scotland.

Five thousand six hundred sixty specimens were received in the first year for f-Hb examination (Fig. 1). Further investigation in secondary care was requested via the portal for 4072 patients and 2881 of these returned a specimen for $\mathrm{f}-\mathrm{Hb}$ examination: at the end of the first year, 1447 patients had completed a FIT and had undergone colonoscopy in secondary care (group A). The utility of the FAST score was examined in this group A.

2521 patients who had submitted FIT samples were not associated with an immediate referral. The potential utility of the FAST score in this group B was also assessed and outcomes for patients followed for approximately one further year to assess whether subsequent referral had occurred and whether SBD had been missed. In addition, linkage with the Scottish Cancer Registry was performed to ensure that all cases of CRC had been identified in both groups A and B.

The FAST score was calculated as detailed earlier using logistic regression, following a univariate analysis using generalized additive models with smoothing splines for continuous variables. Regression coefficients which were used to construct a CRC prediction score, where the dependent variable was the presence or absence of CRC [14]. For $\mathrm{f}-\mathrm{Hb} 0 \mu \mathrm{g} \mathrm{Hb} / \mathrm{g}$ faeces, $\mathrm{f}-\mathrm{Hb}$ score $=0$, if $\mathrm{f}-\mathrm{Hb}$ from 1 to $19 \mu \mathrm{g} \mathrm{Hb} / \mathrm{g}$ faeces, score $=0.684$, if $\mathrm{f}-\mathrm{Hb}$ from 20 to $199 \mu \mathrm{g} \mathrm{Hb} / \mathrm{g}$ faeces, score $=2.824$ and, if $\mathrm{f}-\mathrm{Hb} \geq 200 \mu \mathrm{g}$ $\mathrm{Hb} / \mathrm{g}$ faeces, score $=4.184$. Then, the FAST score $=\mathrm{f}-\mathrm{Hb}$ score $+0.031 \mathrm{x}$ age (years) +0.479 if male. Interpretation is: if the FAST score is $\geq 2.12$, there is a high risk of CRC; a score of $<2.12$ implies that there is little risk of CRC and referral for colonoscopy would be of limited value. The threshold for the $\beta$-coefficient of the FAST score with 99\% clinical sensitivity was 2.12 and was at least that in $88.0 \%$ of the patients included in the derivation cohort.

MedCalc statistical software (MedCalc Software, Mariakerke, Belgium) was used for all calculations. All data were gathered within routine patient care, therefore ethical approval was not required.

\section{Results}

Group A comprised 1447 patients with new bowel symptoms who completed a FIT and were referred to secondary care and for whom colonoscopy data, and histology if required, were available: 780 (53.9\%) of these had $\mathrm{f}-\mathrm{Hb} \geq 10 \mu \mathrm{g} \mathrm{Hb} / \mathrm{g}$ faces. There were 296 with SBD of whom 252 had a positive $\mathrm{f}-\mathrm{Hb}$ result $(\mathrm{f}-\mathrm{Hb} \geq 10 \mu \mathrm{g}$ $\mathrm{Hb} / \mathrm{g}$ faeces) and 1151 without SBD of whom $623 \mathrm{had}$ a negative $\mathrm{f}-\mathrm{Hb}$ result (f- $\mathrm{Hb}<10 \mu \mathrm{g} \mathrm{Hb} / \mathrm{g}$ faeces). Using a FAST score with $\geq 2.12$ as the cut-off so as to give $99 \%$ clinical sensitivity for CRC according to its developers [14], only 1143 of the 1447 would have been referred for colonoscopy, a $21.0 \%$ reduction in colonoscopy demand. Of the 296 with SBD, 286 had a positive FAST score. Of the 1151 without SBD, only 294 had a negative FAST score. The ten cases detected by $\mathrm{f}-\mathrm{Hb}$ and other information, but not by the FAST score, were one CRC, five $\mathrm{AA}$ and four IBD. Further investigation of referral data for these cases revealed that the patient with CRC was referred due to iron deficiency anaemia (IDA). Three of the five AA reported persistent diarrhoea, one had rectal bleeding and the remaining AA was a lesion which had been palpated upon digital rectal examination by the GP. Of the four cases of IBD associated with a negative FAST score, two reported rectal bleeding and two had a change in bowel habit.

The number of colonoscopies required, number (percentage) with CRC and SBD, and positive predictive value, negative predictive value, sensitivity and specificity, with 95\% confidence intervals (CI), for both CRC and SBD in the 1143 patients in group A with FAST score $\geq 2.12$ are shown in Table 1.

Of the 2521 in group B who were not immediately referred from primary care for colonoscopy, only $4.8 \%$ had $\mathrm{f}-\mathrm{Hb} \geq 10 \mu \mathrm{g} \mathrm{Hb} / \mathrm{g}$ faeces. In marked contrast, 1349 $(53.5 \%)$ had FAST score $\geq 2.12$. The majority of these patients with negative $\mathrm{f}-\mathrm{Hb}$ results were not investigated further. Indeed, clinical rationale led to only $122(4.7 \%)$ of these patients ultimately completing bowel investigations. There were 15 cases of SBD subsequently diagnosed: four cases of CRC, five cases of AA and six new cases of IBD. A FAST score $\geq 2.12$ was found in 13 (86.7\%) of these, including all four CRC, which were associated with an initial $\mathrm{f}-\mathrm{Hb}<10 \mu \mathrm{g} \mathrm{Hb} / \mathrm{g}$ faeces, as were three of the five AA and three of the six new cases of IBD.

\section{Discussion}

The published FAST score was derived from a cohort consisting of 1572 consecutive symptomatic patients referred to colonoscopy who were included in the derivation cohort for the COLONPREDICT study. The validation cohort included data from three studies done in Scotland and two in Spain. It was shown that a FAST score $<2.12$ implied that $\mathrm{CRC}$ can be ruled out. This would facilitate the major aim of our use of FIT in assessment of patients presenting with lower bowel symptoms, which is as a "rule-out" test, thereby directing the 


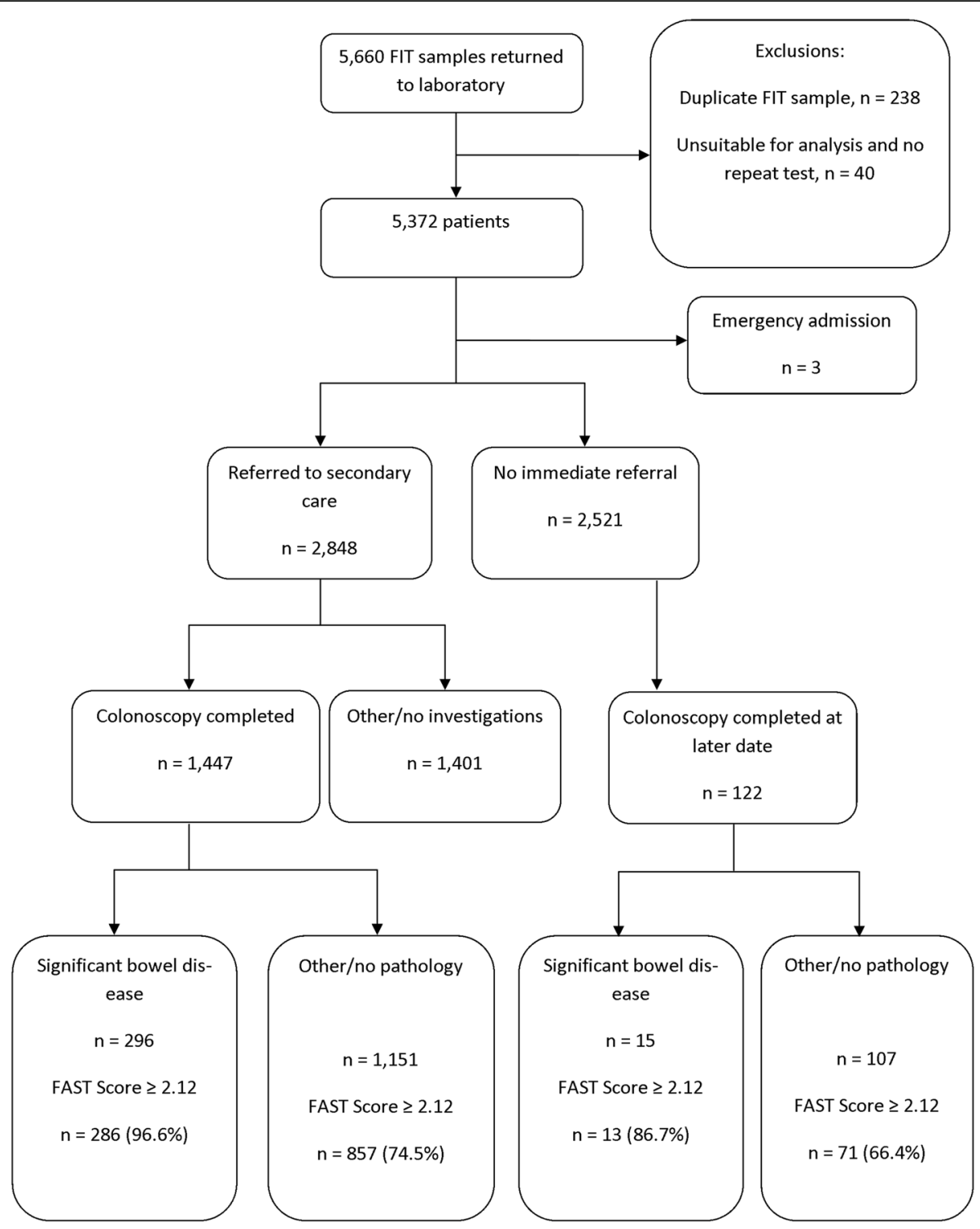

Fig. 1 Study flow diagram

Table 1 Outcomes for 1143 patients with FAST score $\geq 2.12$ in 1447 referred patients with both faecal haemoglobin concentration and colonoscopy results

\begin{tabular}{lll}
\hline Outcome & $\begin{array}{l}\text { Colorectal cancer (CRC) in the 1143 } \\
\text { with FAST score } \geq 2.12\end{array}$ & $\begin{array}{l}\text { Significant bowel disease (SBD) in the 1143 } \\
\text { with FAST score } \geq 2.12\end{array}$ \\
\hline No. of colonoscopies & 1143 & 1143 \\
No (\%) with disease & $94(8.2)$ & $286(25.0)$ \\
Positive predictive value (\%) with (95\% Cl) & $8.2(8.0-8.5)$ & $25.0(24.3-25.8)$ \\
Negative predictive value (\%) with (95\% Cl) & $98.9(97.7-100.0)$ & $96.7(94.1-98.2)$ \\
Sensitivity (\%) with (95\% Cl) & $99.0(94.3-100.0)$ & $96.6(93.9-98.4)$ \\
Specificity (\%) with (95\% Cl) & $22.4(20.2-24.7)$ & $25.5(23.1-28.2)$ \\
\hline
\end{tabular}


somewhat limited colonoscopy resource available to those who would benefit most and, more importantly, reassuring those with a low FAST score that the likelihood of SBD was low. However, safety-netting approaches, including watching and waiting, should be in place for those who continue to complain of symptoms [10]. In addition, it was acknowledged that the patients included in all of the studies included in the derivation and validation of the score had been selected a priori by health care professionals for further evaluation. Further, it was stated that it was considered that the diagnostic accuracy of the FAST score should be externally evaluated in patients presenting in primary care with lower bowel symptoms before its use was extensively adopted. The recent work of Herrero et al. [15] demonstrated that $88.0 \%$ of the 1572 in the COLONPREDICT cohort studied had a FAST score $\geq 2.12$ : thus, few (only 12.0\%) would be deemed to have a low risk of CRC and not require colonoscopy. The clinical sensitivity for the FAST score $\geq 2.12$ was $100.0 \%$ (95\% CI: $97.8-100.0$ ) and $93.7 \%$ (95\% CI: 95.9-98.9) for CRC and SBD respectively, and the specificity was $13.9 \%$ (95\% CI: $12.1-15.9$ ) and $16.1 \%$ (95\% CI: 14.0-18.4). However, a major caveat is that the data used, from the COLONPREDICT study, were those used as the derivation cohort for development of the FAST score.

In contrast, our analysis of the application of the FAST score in patients referred from primary care with lower bowel symptoms, on whom both $\mathrm{f}-\mathrm{Hb}$ and colonoscopy data were available, demonstrated that the colonoscopy demand would be reduced using a FAST score $\geq 2.12$ cut-off. The clinical performance characteristics for CRC and SBD are shown in Table 1 . The sensitivity and specificity in group A were lower and higher, respectively, from those found in the recent study of Herrero et al. on the use of the FAST score [15]. This might be because their group has significant differences to ours, particularly the higher prevalence of CRC and SBD. Eight cases of SBD would have been missed if the FAST score $\geq 2.12$ was used as compared to $\mathrm{f}-\mathrm{Hb}$ plus clinical data, but only one case of CRC, which would have been referred anyway and not missed clinically, since the patient had IDA. However, a limitation of our study is that group A had been referred to secondary care without use of the FAST score: thus, in this study, the use of the FAST score has actually been examined as a potential followup investigation prior to acceptance into colonoscopy, assessing whether the score, applied after referral on the grounds of clinical findings and $\mathrm{f}-\mathrm{Hb}$, would lead to a reduction in colonoscopies: it does, but a small number of patients with CRC and SBD would be missed, a less than ideal finding. Further examination of the cases of SBD which would be missed if the FAST score had been applied showed the importance of clinical rationale, because all 15 had what some would term "red flag" symptoms. However, similar symptoms were also reported by the majority of the remaining 294 referred patients who also had a negative FAST score, but did not have SBD; 96 had IDA, 78 had rectal bleeding, 46 had persistent diarrhoea and 47 had a change in bowel habit. A prospective study, using the FAST score as the initial triage tool in routine practice therefore seems to be warranted from both our data and those of Herrero et al. [15]

In those in group B, who were not referred, possibly in the main because $95.0 \%$ had $\mathrm{f}-\mathrm{Hb}<10 \mu \mathrm{g} \mathrm{Hb} / \mathrm{g}$ faeces, over $50 \%$ had a FAST score $>2.12$ and thus, if this became the criterion for referral, many more colonoscopies would be required, without much evidence of the value of further investigations in this group. One concern, worthy of further examination, is that the current score means that all males over 53 years would be referred as would all females over 68 years and this is the major reason why the score has such high positivity in patients in group B that were not referred by GP for further investigation. However, clinical rationale led to only $122(4.7 \%)$ being further investigation over the subsequent year. Interestingly, despite $\mathrm{f}-\mathrm{Hb}<10 \mu \mathrm{g} \mathrm{Hb} / \mathrm{g}$ faeces, the FAST score again detected all four CRC found in this group. It also would have detected all five AA and four out of six IBD, but the specificity would be very low. A clear limitation of this study is that colonoscopy was not performed on all of group B, but this reflects real routine practice. Subsequent linkage with the Scottish Cancer Registry confirmed that all patients with CRC in this group were identified.

\section{Conclusions}

As a result of this study, we cannot support use of the published FAST score formula [15] to assist in deciding who to refer for colonoscopy, since SBD was missed in those who had been referred using $\mathrm{f}-\mathrm{Hb}$ and other considerations: further, the positivity was more than $50 \%$ in those not referred. In the original development of the FAST score, it was admitted that a limitation was the reduced diagnostic accuracy for detection of not only CRC, but additional SBD, possibly because the covariate pattern which predicts CRC may be different to that which predicts other bowel diseases. On the other hand, although this reduced accuracy could be considered as a limitation, there are several cogent arguments to support use of the FAST score in this broader clinical perspective [14]. However, we believe that the score could be improved. One major concern is that the published score has $\mathrm{f}-\mathrm{Hb}$ groups based on the analytical performance characteristics of the OC-Sensor (Eiken Chemical Co., Ltd., Tokyo, Japan), which has an analytical working range of $10-200 \mu \mathrm{g} \mathrm{Hb} / \mathrm{g}$ faeces, and the $20 \mu \mathrm{g} \mathrm{Hb} / \mathrm{g}$ 
faeces used in the formula was selected during development as the most commonly applied $\mathrm{f}-\mathrm{Hb}$ cut-off in CRC screening. We used a different FIT analytical system. Albeit that our original development and validation of the FAST score suggested that there were no interanalyser differences [10], we think that a FAST score with $\mathrm{f}-\mathrm{Hb}$ groups of $<10,10-400$ and $>400 \mu \mathrm{g} \mathrm{Hb} / \mathrm{g}$ faeces should be created for the FIT system most widely used in the UK for assessment of symptomatic patients (HM-JACKarc, Kyowa Medex Co., Ltd., Tokyo, Japan): groups such as this are required because $\mathrm{f}-\mathrm{Hb}$ does not have a normal distribution, even after logarithmic transformation, and these groups are used in our and others' current routine application of FIT in routine practice. This concept, that different FIT analytical systems may require different FAST score formulae, is supported by the results from a recent study [17]. A comparison showed that the new COLONFIT score, which includes the maximum $\mathrm{f}-\mathrm{Hb}$ of three samples and the number of samples with $\mathrm{f}-\mathrm{Hb}>4 \mu \mathrm{g} \mathrm{Hb} / \mathrm{g}$ faeces in addition to other variables, classified patients $3-4 \%$ better than the FAST score in both the derivation and validation cohorts. It was suggested that further studies on a direct comparison of both scores are needed to assess if the 3$4 \%$ gain in classification could be offset by lower adherence through the requirement for three faecal samples rather than one. Importantly, however, the FIT analytical system (iFOB, Linear Chemicals SL, Barcelona, Spain), which was said to be able to detect $\mathrm{f}-\mathrm{Hb}$ of $4 \mu \mathrm{g} \mathrm{Hb} / \mathrm{g}$ faeces, was different to that used to derive the FAST score and that used in this study. The performance of the FAST score with this FIT analytical system perhaps could have been improved as suggested above, but with different and appropriate $\mathrm{f}-\mathrm{Hb}$ groups.

Moreover, it may be that there is benefit in using lower $\mathrm{f}-\mathrm{Hb}$ cut-offs than the $10 \mu \mathrm{g} \mathrm{Hb} / \mathrm{g}$ faeces recommended in DG30 [8], for example, using the limit of detection $(2 \mu \mathrm{g} \mathrm{Hb} / \mathrm{g}$ faeces for the FIT analytical system used in this study) or the limit of quantitation $(7 \mu \mathrm{g} \mathrm{Hb} /$ g faeces) [18]. Although we have recently suggested that $\mathrm{f}-\mathrm{Hb}$ is the most important factor to be considered when deciding which patients presenting in primary care with lower bowel symptoms would benefit most from referral for colonoscopy [19], we plan to create a number of scores and examine the use of these including lower $\mathrm{f}$ $\mathrm{Hb}$ cut-offs derived from the detectability characteristics of the FIT system used, which do differ between FIT systems [18]. Ideally, this should be done prospectively in our now routine use of FIT in assessment of most patients presenting in primary care [16], other than those with rectal bleeding, IDA, or a mass, although the application of the FAST score does warrant further study in such patients, who are currently deemed to be at high risk. In addition, further risk scores that include $\mathrm{f}-\mathrm{Hb}$ and other variables, should be developed and investigated prospectively.

\section{Abbreviations}

AA: advanced adenoma; CHI: Community Health Index; CRC: colorectal cancer; DG: diagnostics guidance; f-Hb: faecal haemoglobin concentration; FIT: faecal immunochemical test for haemoglobin; GP: general practitioner; IDA: iron deficiency anaemia; NG: NICE guideline; NICE: National Institute for Health and Care Excellence; SBD: significant bowel disease; UK: United Kingdom

\section{Acknowledgements}

Lynne Taylor, Department of Blood Sciences, Ninewells Hospital and |Medical School, Dundee, made up and distributed FIT kits to GP practices.

Alpha Laboratories Ltd., Eastleigh, Hants, are thanked for their support for the laboratory analyses.

\section{Consent to publish}

Not required by the institutions of the authors.

\section{Authors' contributions}

All authors participated in the original development and validation of the FAST score. CGF, JD and RJCS lead the conception and planning of this study. JD and CGF performed the initial data analysis. CM was the lead clinician responsible for patient care. JAS supervised the analyses of faecal haemoglobin. All authors contributed significantly to the writing of this paper. CGF and JD prepared the final submitted version. All authors have read and approved the manuscript.

\section{Funding}

No specific funding was received for this study. JD was supported by a grant from the Chief Scientist Office, Scotland, grant number ASM/14/4. This funding body had no role in the design of the study and collection, analysis, and interpretation of data and in writing the manuscript.

\section{Availability of data and materials}

The datasets used and analysed during the current study are available from the corresponding author on reasonable request.

Ethics approval and consent to participate

Associated studies were approved by the North of Scotland Research Ethics Committee (reference number 15/NS/0101). The Ethics Committee stated that submission of a single faecal sample for FIT analysis was considered as consent. Ethical approval was not required for this particular evaluation of the FAST Score using anonymised data obtained from routine use of faecal haemoglobin analyses in the investigation of patients presenting in primary care with lower bowel symptoms.

\section{Competing interests}

CGF has undertaken consultancy with Immunostics Inc., Ocean, NJ, USA, and Kyowa Medex Co., Ltd., Tokyo, Japan, and received assistance for travel and attendance at meetings from Alpha Labs Ltd., Eastleigh, Hants, UK. All other authors declare no potential conflicts of interest with respect to the research, authorship, and/or publication of this article.

\section{Author details}

${ }^{1}$ Centre for Research into Cancer Prevention and Screening, University of Dundee, Dundee, Scotland, UK. ${ }^{2}$ Blood Sciences and Scottish Bowel Screening Laboratory, Ninewells Hospital and Medical School, Dundee, Scotland, UK. ${ }^{3}$ Department of Gastroenterology, Ninewells Hospital and Medical School, Dundee, Scotland, UK. ${ }^{4}$ Centre for Research into Cancer Prevention and Screening, University of Dundee, Dundee, Scotland, UK ${ }^{5}$ Centre for Research into Cancer Prevention and Screening, University of Dundee, Ninewells Hospital and Medical School, Dundee, Scotland DD1 9SY, UK. 
Received: 26 February 2019 Accepted: 4 December 2019

Published online: 11 December 2019

\section{References}

1. Young GP, Symonds EL, Allison JE, Cole SR, Fraser CG, Halloran SP, et al. Advances in fecal occult blood tests: the FIT revolution. Dig Dis Sci. 2015;60: 609-22. https://doi.org/10.1007/s10620-014-3445-3.

2. Cancer Research UK. 2018. Bowel cancer incidence statistics. https://www. cancerresearchuk.org/health-professional/cancer-statistics/statistics-bycancer-type/bowel-cancer/incidence

3. Vega P, Valentín F, Cubiella J. Colorectal cancer diagnosis: pitfalls and opportunities. World J Gastrointest Oncol. 2015;7:422-33. https://doi.org/10. 4251/wjgo.v7.112.422

4. Quyn AJ, Steele RJ, Digby J, Strachan JA, Mowat C, McDonald PJ, et al. Application of NICE guideline NG12 to the initial assessment of patients with lower gastrointestinal symptoms: not FIT for purpose? Ann Clin Biochem. 2018:55:69-76. https://doi.org/10.1177/0004563217707981.

5. Westwood M, Lang S, Armstrong N, van Turenhout S, Cubiella J, Stirk L, et al. Faecal immunochemical tests (FIT) can help to rule out colorectal cancer in patients presenting in primary care with lower abdominal symptoms: a systematic review conducted to inform new NICE DG30 diagnostic guidance. BMC Med. 2017;15:189. https://doi.org/10.1186/s12916017-0944-z.

6. Fraser CG. Faecal immunochemical tests (FIT) in the assessment of patients presenting with lower bowel symptoms: concepts and challenges. Surgeon. 2018;16:302-8. https://doi.org/10.1016/j.surge.2018.01.004.

7. Fraser CG. Faecal immunochemical tests for haemoglobin (FIT) in the assessment of patients with lower abdominal symptoms: current controversies. Gastroenterol Hepatol. 2019;42:263-70. https://doi.org/10. 1016/j.gastrohep.2018.09.007.

8. National Institute for Health and Care Excellence (NICE). Quantitative faecal immunochemical tests to guide referral for colorectal cancer in primary care. Diagnostics guidance DG30, 2017. https://www.nice.org.uk/guidance/dg30

9. National Institute for Health and Care Excellence (NICE). Suspected cancer: recognition and referral. NICE Guideline NG12, 2017. https://www.nice.org. uk/guidance/ng12

10. Godber IM, Benton SC, Fraser CG. Setting up a service for a faecal immunochemical test for haemoglobin (FIT): a review of considerations, challenges and constraints. J Clin Pathol. 2018;71:1041-5. https://doi.org/10. 1136/jclinpath-2018-205047.

11. Williams TG, Cubiella J, Griffin SJ, Walter FM, Usher-Smith JA. Risk prediction models for colorectal cancer in people with symptoms: a systematic review. BMC Gastroenterol. 16:63. https://doi.org/10.1186/s12876-016-0475-7.

12. Cubiella J, Vega P, Salve M, Díaz-Ondina M, Alves MT, Quintero E, et al. Development and external validation of a faecal immunochemical testbased prediction model for colorectal cancer detection in symptomatic patients. BMC Med. 2016;14:128. https://doi.org/10.1186/s12916-016-0668-5.

13. Fraser CG, Rubeca T, Rapi S, Chen LS, Chen HH. Faecal haemoglobin concentrations vary with sex and age, but data are not transferable across geography for colorectal cancer screening. Clin Chem Lab Med. 2014:52: 1211-6. https://doi.org/10.1515/cclm-2014-0115.

14. Cubiella J, Digby J, Rodríguez-Alonso L, Vega P, Salve M, Díaz-Ondina M et al. The fecal hemoglobin concentration, age and sex test score: development and external validation of a simple prediction tool for colorectal cancer detection in symptomatic patients. Int J Cancer. 2017;140: 2201-11. https://doi.org/10.1002/ijc.30639.

15. Herrero JM, Vega P, Salve M, Bujanda L, Cubiella J. Symptom or faecal immunochemical test based referral criteria for colorectal cancer detection in symptomatic patients: a diagnostic tests study. BMC Gastroenterol. 2018; 18:155. https://doi.org/10.1186/s12876-018-0887-7.

16. Mowat C, Digby J, Strachan JA, McCann R, Hall C, Heather D, et al. Impact of introducing a faecal immunochemical test (FIT) for haemoglobin into primary care on the outcome of patients with new bowel symptoms: a prospective cohort study. BMJ Open Gastroenterol. 6:e000293. https://doi. org/10.1136/bmjgast-2019-000293.

17. Fernández-Bañares F, Clèries R, Boadas J, Ribes J, Oliva JC, Alsius A, et al. Prediction of advanced colonic neoplasm in symptomatic patients: a scoring system to prioritize colonoscopy (COLONOFIT study). BMC Cancer. 2019;19:734. https://doi.org/10.1186/s12885-019-5926-4.

18. Fraser CG, Benton SC. Detection capability of quantitative faecal immunochemical tests for haemoglobin (FIT) and reporting of low faecal haemoglobin concentrations. Clin Chem Lab Med. 2019;57:611-6. https:// doi.org/10.1515/cclm-2018-0464.

19. Digby J, Steele RJ, Strachan JA, Mowat C, Anderson AS, McCann R, et al. Do other variables add value to assessment of the risk of colorectal disease using faecal immunochemical tests for haemoglobin? Ann Clin Biochem. 2019;56:472-9. https://doi.org/10.1177/0004563219839423.

\section{Publisher's Note}

Springer Nature remains neutral with regard to jurisdictional claims in published maps and institutional affiliations.
Ready to submit your research? Choose BMC and benefit from:

- fast, convenient online submission

- thorough peer review by experienced researchers in your field

- rapid publication on acceptance

- support for research data, including large and complex data types

- gold Open Access which fosters wider collaboration and increased citations

- maximum visibility for your research: over $100 \mathrm{M}$ website views per year

At BMC, research is always in progress.

Learn more biomedcentral.com/submissions 